\title{
Bhopal Gas tragedy- An experience of the medical and dental practitioners of this Unfinished Story 1984
}

\author{
Dr. Shubhangi Mhaske ${ }^{1}$, Dr. Nitin Awasthi ${ }^{2}$, Dr. Swati Saawarn ${ }^{3}$, \\ Dr. Raju Ragavendra $\mathrm{T}^{4}$, Dr. Abhishek Gouraha ${ }^{5}$, Dr. Uravshi Tomar ${ }^{6}$ \\ ${ }^{1-6}$ Department of Oral Pathology, People's Dental Academy, Bhopal, Madhya Pradesh, India
}

\begin{abstract}
Background and Objectives: Bhopal Gas Tragedy is the mankind worst industrial disaster resulted in deaths around 200,000 people. There are more than 5, 00,000 registered survivors of the tragedy. Various studies have been conducted that provide a strong evidence of disastrous influence of the gas on affected individuals and provide data that reveals unique abnormalities.

The study aimed to record the effects of this gas on the craniofacial system after 28 years of disaster through the experience of Medical and Dental practitioners and to open up new possibilities for further research on this tragic event.

Methods: 60 individuals were selected for the study. This includes 30 medical practitioners and 30 dental practitioners. All the practitioners had a working experience of more than 20 years. Many of the practitioners had been posted in the area affected by gas. A simple questionnaire consisting a list 19 questions was prepared and printed in English.

Results: Frequencies and percentage distribution of the answers were calculated for medical practitioners and dental practitioners. Many of the practitioners were aware about the acute and chronic effects of the gas on vital systems of the body but were less aware about the craniofacial and dental effects which were told by only few dental practitioners.

Interpretation and conclusions: Majority of the studies concentrated on the systemic effect of the gas exposure rather than craniofacial defects/effects. Less awareness within study group as well as scanty knowledge about craniofacial and dental effects of the dreaded gas.
\end{abstract}

Keywords: Craniofacial, Dental effects, Dental practitioners, Industrial disaster, Medical practitioners, Methyl isocyanate

\section{INTRODUCTION}

The Bhopal Gas Tragedy is considered as the world's worst man made chemical disaster. During the midnight of December 2-3, 1984, a storage tank exploded which contained lethal methyl isocyanate (MIC) used in the production of pesticides at the Union Carbide India Limited (UCIL) pesticide plant resulted in the release of 30-40 tons of this toxic gas, methyl isocyanate (MIC) spreading over approximately 30 square miles, killing thousands of people and gravely injuring hundreds of thousands [1]. More than half a million people were considered to be exposed to the MIC gas. Several epidemiological studies conducted soon after the accident showed significant morbidity and increased mortality in the exposed population. Studies have shown that these survivors still experience a higher incidence of reported health problems including febrile illnesses, respiratory, neurological, psychiatric and ophthalmic symptoms [2,3] leading to the difficulty in continuing the normal life.

Majority of the epidemiological and cohort studies have concentrated on the systemic health problems and data on dental or craniofacial manifestations observed in affected individuals and their off-springs is not available in literature. Further, there are no studies specifically elaborating the assessment of clinical experience of dental and medical practitioners over a span of their career in affected area. This lead us to carry out the present study which also may help in creating awareness about craniofacial/dental effects in patients not only among the medical consultants but also dental practitioners.

\section{MATERIAL AND MethodS}

This questionnaire based study was designed for the medical and dental health care providers practicing in the gas tragedy affected area. A questionnaire consisting of 19 simple questions was prepared in a logical manner. A total of $60 ; 30$ medical \& 30 dental practitioners were selected for the study. The study included only those health care providers who have been practicing since the tragic event took place. Many of these practitioners had actually witnessed the incident themselves but were saved as they were not residing in the affected zone. The data was collected by personal interviews. 


\section{General Practitioners perspective-}

\section{RESUlTS}

The data from the questionnaires was tabulated and statistically analyzed in the statistical program SPSS software (version 20.0) for Windows. The study response rate was $82 \%$. Frequencies and percentage distribution of the responses were calculated separately for medical \& dental practitioners.

Majorities (77\%) of medical practitioners (Fig 1) were well aware of complication and late effects of exposure to the MIC and they had observed that acute respiratory distress syndrome was the major cause of death due to MIC gas exposure. Medical practitioners (67\%) were of the opinion that high concentration of MIC caused an increase in the incidence of miscarriage in expectant mothers. Medical practitioners (70\%) had a difference of opinion on the issue of any psychological and neurological effects on the survivors. About $64 \%$ of them believed that MIC has a carcinogenetic potential but none of them have come across any specific type of malignancy. The most alarming issue was that the $47 \%$ consultant observed serious teratogenic effects like phoecamelia, hydrocephalus etc during their practicing experience. The UCIL factory was closed immediately after the incident. But the raw material residue was not disposed and toxic substances lie still in the factory premises. When asked about the health hazards due to contamination of soil and ground water, the medical practitioners (87\%) agreed that they have read in literature about this fact.

\section{Dental Practitioner's perspective}

Few dental consultants observed dental anomalies such as Dents in dente, Dens evaginatus during their practicing experience and they were in consensus that the abnormalities in the dentition is due to acute or chronic exposure to MIC. About $60 \%$ of them have come across such findings. $40 \%$ of dental practitioners were aware of the craniofacial defects due to MIC exposure (Fig 2). Craniofacial defects/symptoms observed by most of them included cleft lip and palate. About $64 \%$ of them believe that exposure to MIC can be responsible for increase in cancer incidence in those patients without any other specific etiology. Only about $50 \%$ dental practitioners were aware about the neurological effects caused by short and long term exposure to high concentration of MIC. 57\% of dental practitioners were aware of the Union carbide waste disposal.

\section{FIGURES AND TABLES \\ Table I- Properties of MIC}

\begin{tabular}{|l|l|}
\hline \multicolumn{1}{|c|}{ Physical properties } & \multicolumn{1}{c|}{ Chemical properties } \\
\hline Boiling Point- $39^{0} \mathrm{C}$ & Moderately soluble in water \\
Freezing Point- $-80^{\circ} \mathrm{C}$ & Hydrolyse to form carbo dioxide and methylamine \\
Specific Gravity- 0.96 & MIC pyrolised between $427{ }^{0} \mathrm{C}$ and $548^{0} \mathrm{C}$ and \\
Molecular Weight- 57.1 & decomposes to hydrogen cyanide $(\mathrm{HCN})$ and \\
Vapor pressure- $348 \mathrm{~mm} \mathrm{Hg}$ at $20^{\circ} \mathrm{C}$ & carbondioxide \\
\hline
\end{tabular}

Table II Lethal dose (LD)/ Lethal Concentration (LC) Values for Methyl Isocyanate, from Animal Studies

\begin{tabular}{|l|l|l|l|}
\hline Route & Dose & Model & LD50/LC50 \\
\hline Oral & $10 \%$ sol; single dose & Male rat & $71 \mathrm{mg} / \mathrm{kg}$ \\
Inhalation & Vapors (4 hr) & Rat & $1.25 \mathrm{mg} / \mathrm{m} 3$ \\
Skin & Undiluted & Rabbit & $0.22 \mathrm{ml} / \mathrm{kg}$ \\
\hline
\end{tabular}

Table III- Acute effects of MIC observed in the individuals in accordance with the ICMR reports

\begin{tabular}{|l|l|}
\hline $\begin{array}{l}\text { Physiological systems } \\
\text { affected }\end{array}$ & Clinical Symptoms \\
\hline Respiratory & Breathlessness, chest pain, pulmonary distress, severe dry or wet cough \\
Ocular & $\begin{array}{l}\text { Burning, intense irritation, blurred vision, photophobia, corneal ulcer } \\
\text { Spontaneous miscarriages, still birth, fetal abnormalities }\end{array}$ \\
Reproductive & $\begin{array}{l}\text { Anxiety, neurotic depression, impaired auditory and visual memory, } \\
\text { sensory and motor dysfunctions }\end{array}$ \\
$\begin{array}{l}\text { Psychological and } \\
\text { neurological } \\
\text { Gastrointestinal }\end{array}$ & Persistent diarrhea, abdominal pain, anorexia. \\
\hline
\end{tabular}

Table IV-Chronic effects of MIC after 6months of exposure in accordance with ICMR reports

\begin{tabular}{|l|l|}
\hline Physiological systems affected & Clinical Symptoms \\
\hline Respiratory & $\begin{array}{l}\text { Decreased lung functions, obstructive airway diseases, cough with or without } \\
\text { expectorations, wheezing, dyspnoea }\end{array}$ \\
Ocular & Corneal opacities, conjunctivitis, damage to ocular chamber, deficiency of tear secretions
\end{tabular}




\begin{tabular}{|l|l|}
\hline Reproductive & $\begin{array}{l}\text { Increased pregnancy loss, infant mortality, decreased fetal weight } \\
\text { Psychological and neurological }\end{array}$ \\
Cancer & $\begin{array}{l}\text { Marginal increase in oropharyngeal cancer incidence } \\
\text { Growth retardation }\end{array}$ \\
Growth pattern & Hyper-responsiveness of immune system \\
Immune system & \\
\hline
\end{tabular}

Table V- Effects observed in the individuals after 28 years of disaster through the experience of Practitioners

\begin{tabular}{|l|l|}
\hline Physiological system affected & \multicolumn{1}{c|}{ Clinical symptoms } \\
\hline Respiratory system & Breathlessness, pulmonary edema, bronchiectasis \\
Ocular systems & Burning sensation, muscular weakening, corneal opacity, conjunctivitis, \\
Psychological and neurological system & corneal congestion \\
Reproductive system & Anxiety, neurotic depression, loss of memory at an early age. \\
Genotoxic, immunologic and cancer development & Miscarriage, still borns, fetal anomalies, decreased fetal weight \\
Craniofacial anomalies & Increasing incidence of breast carcinoma, uterine carcinoma, \\
& oropharyngeal carcinoma, decreased immune response, marked \\
cytogenetic abnormalities, p53 mutation. & Cleft lip and palate, dens indente, dens evaginatus, amelogenesis \\
& imperfecta, dentinogenesis imperfecta, etc \\
\hline
\end{tabular}

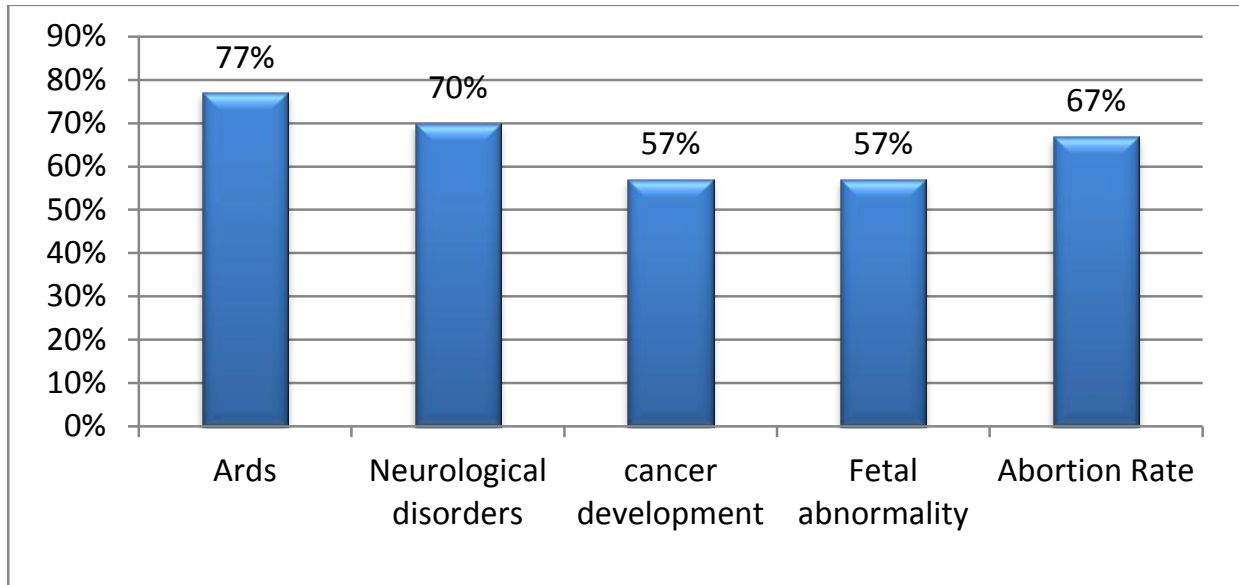

Figure 1: Percentage of medical practitioners and the associated disorders reported by them

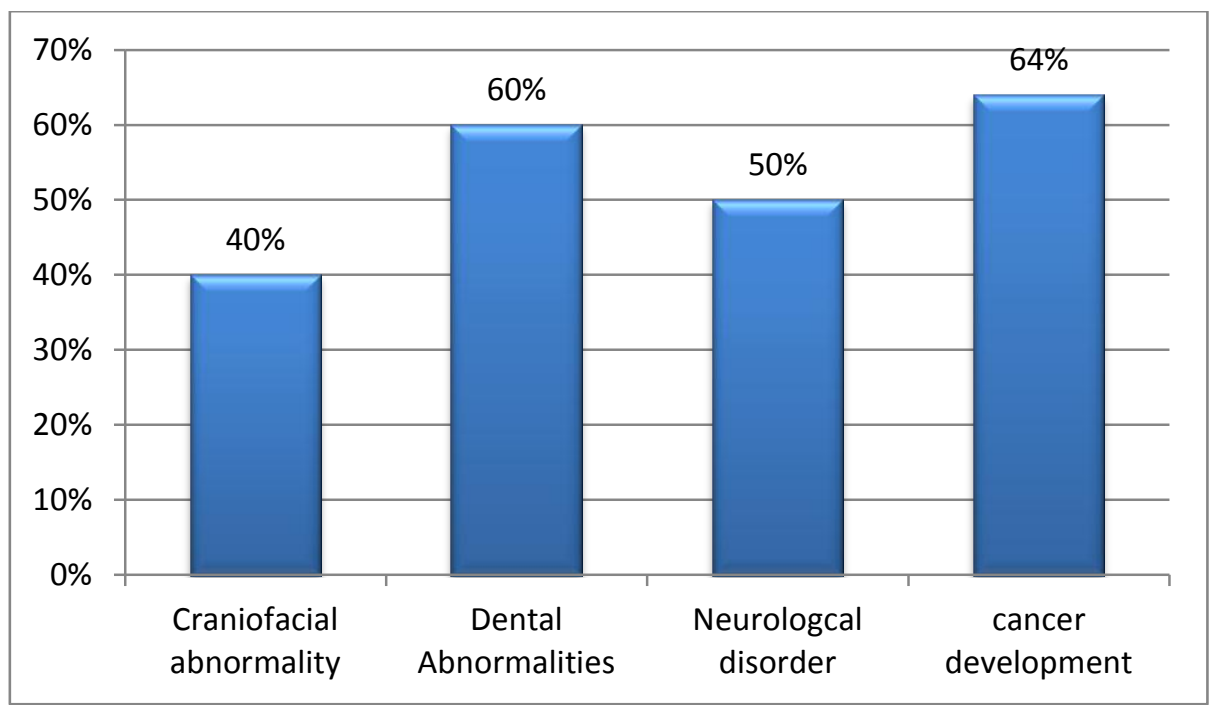

Figure 2: Percentage of dental practitioners and the disorders reported by them 


\section{Discussion}

Bhopal gas tragedy has been documented as one of the world's worst manmade disasters [4]. Union carbide pesticide plant was set up in Bhopal, India to produce 'Sevin' which was a fatal toxic pesticide to be used to combat fodder pest havoc in Mexico, Central America, Malaysia, Japan and Southern Europe. To manufacture Sevin (Carbaryl), phosgene gas was reacted with mono methyl amine to produce this new molecule. Methyl isocyanide (MIC) a by-product of same is the most dangerous compounds ever invented in chemical history, ${ }^{[5]}$. The properties and lethal dose of MIC is illustrated in Table I and II.

The Indian Council Of Medical Research (ICMR) was one of the foremost organization to initiate and publish clinical research studies in their reports on this tragedy [6] (Table III and Table IV). According to ICMR, a large fraction of population continues to be chronically ill with diseases of respiratory, gastrointestinal, musculoskeletal, neurological and other systems. As the vital systems were affected gravely, the dental and craniofacial anomalies were probably ignored or not documented in these studies as they were not so significant. This study was designed to explore and document the possible dental and craniofacial effects seen in the affected individuals and subsequent generations. This along with other studies strongly emphasizes the need for continued vigilance of the long term morbidity due to MIC including its effect on oral, dental \& craniofacial structures. However in the last 28 years, migration of people both in and out of this population has affected the cohort and may have caused a deception in the practitioner's purview and this may be a limitation of this study. Also considering the numerous ethical, legal, economic and political concerns, the nature and magnitude of effects still remain uncertain.

The initial human autopsy studies, which revealed severe necrotizing lesions in the lining of the upper respiratory tract as well as in the bronchioles, alveoli, and lung capillaries, suggested that the respiratory system was most severely affected. ICMR has concluded in its report that asphyxia arising from acute lung injury or Acute Respiratory Distress Syndrome (ARDS) could be central to most deaths [1]. Furthermore, autopsies indicated generalized visceral congestion, cerebral edema, and anoxic brain damage [7]. Follow-up studies were conducted 2.5-3 months after the accident on a total of 1,279 exposed men, women, and children [8]. In our study, majority of medical practitioners $(77 \%)$ opined that Acute respiratory distress syndrome was the major cause of death due MIC while (47\%) of dental practitioners believed that chronic obstructive pulmonary disease is the major cause.

Findings from early ocular studies conducted 8-60 days after exposure to MIC revealed predominantly injuries resulting from the intensely irritating effect of MIC on the cornea causing severe ocular burning, watering, pain, and photophobia [9]. Follow-up ocular studies, conducted 9 months [10] to 2 yr [11] after exposure, reported chronic irritant symptoms such as persistent eye watering, burning, itching, and redness. Ocular movements were normal in all the subjects [12]. Similar, findings were reported by the medical practitioners and dental practitioner in the present study.

The epidemiological and experimental data reported here clearly indicate that the exposure to MIC can adversely affect the course of pregnancy [13]. An epidemiological survey by Varma showed that miscarriage and infant mortality were high in 865 gas exposed women who lived $1 \mathrm{~km}$ from the plant at the time of the gas leak. Results indicated that $43 \%$ of the pregnancies did not result in a live birth [14]. Of the 486 live births, $14 \%$ of those babies died during the 1st 30 days of life [14]. Clinicians at Bhopal have observed that now the girls who were exposed during their infancy and those in their mother's womb are experiencing 'menstrual chaos' [15]. During an early recovery phase, a comparative survey was undertaken and it was found out that a high incidence of spontaneous miscarriages (24.2\%) in the pregnant women exposed to the toxic gas was observed as compared to those in the control (unexposed) area (5.6\%) [16]. Both medical and dental practitioners (67\%) believed that high concentration of MIC had increased the abortion rates.

The survivors of the Bhopal gas tragedy were reported with significant neurological, neurobehavioral and psychological effects. In a randomized study at ten governments run clinics $22.6 \%$ were found to be suffering from psychological disorders [17]. According to the ICMR, neuromuscular defects, such as tingling numbness, sensation of pins and needles in the extremities, and muscle aches, have continued among the victims after exposure [18]. Srinivasamurthy and Isaac [19] noted that the psychological problems of Bhopal survivors fell into 4 major categories: (1) post-traumatic stress disorders (2) pathological grief reactions, (3) emotional reactions to physical problems - (4) exacerbation of preexisting psychiatric problems. In our study, $70 \%$ of medical practitioners and about $50 \%$ of dental practitioners believed that neurological deficits occurred in the victims.

In one of MIC-exposed animals, cleft palate, reduction in the lengths of the mandible was observed ${ }^{15}$. Development of craniofacial defects in fetus was mostly linked to the concentration MIC at the time of exposure as well as duration of exposure. Majority of the medical practitioners (47\%) as compared to (28\%) dental practitioners also observed fetal abnormalities.

There is essential role of certain signaling pathway such as Muscle specific homobox (Msx), bone morphogenetic protein (Bmp2/ Bmp4) and sonic hedgehog. These genes drive the epithelium and mesenchyme 
interaction that drives cellular proliferation and palate growth. This suggests that genes play a substantial role in facial embryogenesis but environment plays a crucial role in modulating genetic effects [20]. These pesticides act as teratogens that increase the risk of clefting after maternal ingestion.

Few dental practitioners associated with the ICMR survey for the health effects supported the incidence of dental defects also. The anomalies or findings seen were dens in dente or dens invaginatus, dens evaginatus.

The results of the testing of one stored waste sample, six soil samples and one surface water sample within the factory premises and one soil sample from the waste disposal site (solar evaporation pond) clearly shows that the land within the UCIL factory and the waste disposal site is highly contaminated with pesticides, chlorinated benzenes and heavy metals [21]. The total pesticide concentration in the waste sample collected from UCIL premises was as high as $9867 \mathrm{ppm}$ [21]. This high concentration is daily altering the health of inhabitants living nearby. 57\% of dental practitioners agreed that the health hazards were posed due to the Union carbide waste contaminating the soil and groundwater supplies responsible for disruption of ameloblastic cell layer and may be the cause for amelogenesis imperfecta, dentinogenesis imperfecta, fluorosis.

Polychlorinated dibenzo-p-dioxins and dibenzofurans (PCDD/Fs, or dioxins), and polychlorinated biphenyls (PCBs) were also found as toxins in pesticide industrial zone have widespread adverse effects on different species, including humans. Accidental exposure of children to high amounts of PCDD/Fs has been found to be associated with developmental enamel defects and missing permanent teeth. PCDD interferes with mineralization of enamel and dentine and arrests root development. Expression of the specific dioxin receptor (AhR) in dental cells at PCDD-sensitive stages of tooth development suggests that the dental, like other developmental effects of PCDD, are mediated by the AhR. An association between dioxin exposure via mother's milk and developmental mineralization defects in permanent teeth [22]. In accordance with previous studies, high concentration of dioxin levels has been detected in the water supply as well as in soil of the affected area. Also, increased levels of cadmium could affect the crystal formation in the enamel. Biochemical analyses revealed that the catalytic activity of carbonic anhydrase in the immature enamel matrix declined remarkably [23]. The poor catalytic activity of cadmium-binding carbonic anhydrase might hinder the nucleation process, leading to impairment in mineralization [23]. The dental defects and its possible mechanism in Bhopal gas tragedy affected individuals and their preceding generations should be evaluated on a larger scale. The present study conducted had limitations that the findings were solely dependent on the opinion given by the practitioners. More planned long term studies are required to assess the craniofacial and dental anomalies in these exposed generations. Even after 3 decades various effects involving different body systems are present among regional victims and their off springs (Table V).

Severity of the effects had more mortal and morbid aspects and majority of the studies were concentrated on the major vital systemic effects of the MIC gas exposure rather than craniofacial defects/effects. Hence, the present study can help to increase the knowledge and awareness about craniofacial effects among the medical and dental practitioners as well as help in better understanding of the effect of MIC exposure related to in human population.

\section{ACKNOWLEDGEMENT}

I am cordially grateful to all the medical and dental Practitioners of the Bhopal City and Dr. Sudheer Hongal (Reader, Dept of Public Health Dentistry) for their comprehensive and generous support

\section{REFERENCES}

[1]. Mishra PK, Samarth RM, Pathak N, Jain SK, Banerjee S, Maudar KK. Bhopal Gas Tragedy: Review of clinical and experimental findings after 25 years. Int J Occup Med Environ Health ,22(3),2009,193-202.

[2]. Beckett WS. Persistent respiratory effects in survivors of the Bhopal disaster. Thorax.;53 (Suppl 2), 1998, S43-6.

[3]. Vijayan VK, Pandey VP, Sankaran K, Mehrotra Y, Darbari BS, Misra NP. Bronchoalveolar lavage study in victims of toxic gas leak at Bhopal. Indian J Med Res, 90, 1989, 407-14.

[4]. Dhara VR, Dhara R, Acquilla SD, Cullinan P. Personal exposure and long-term health effects in survivors of the Union Carbide disaster at Bhopal. Environ Health Perspect, 110, 2002, 487-500.

[5]. Dhara VR, Dhara R. The Union Carbide Disaster in Bhopal: A Review of Health Effects. Arch Environ Health, 57(5), 2002, 391404.

[6]. Indian Council of Medical Research. Report on Health Effects of the Toxic Gas Leak from the MIC Plant in Bhopal. Bhopal; 2004

[7]. Sriramachari S. The Bhopal Gas Tragedy: An environmental disaster. Curr Sci, 86, 2004, 905-20.

[8]. Gupta BN, Rastogi SK, Chandra H, et al. Effect of exposure to toxic gas on the population of Bhopal. I. Epidemiological, clinical, radiological and behavioral studies. Indian J Exp Biol, 26, 1988, 149-60.

[9]. Andersson N, Muir MK, Mehra V, et al. Exposure and response to methyl isocyanate: results of community-based survey in Bhopal. Br J Ind Med, 45, 1998:469-75.

[10]. Andersson N, Muir MK, Ajwani MK, et al. Persistent eye watering among Bhopal survivors. Lancet. 2, $1986,1152$.

[11]. Khurrum MA, Ahmad HS. Long-term follow up of ocular lesions of methyl isocyanate gas disaster in Bhopal. Indian J Ophthal 35(3), 1987, 36-37.

[12]. Maskari QB. Ophthal survey of Bhopal victims 104 days after the tragedy. J Postgrad Med, 32(4) 1986, 199-202.

[13]. Lepkowski W. Special Report-Bhopal. Chem. Eng. News. 63(48), 1985, 18-32.

[14]. Varma DR. Epidemiological and experimental studies on the effects of methyl isocyanate on the course of pregnancy. Environ Health Perspect, 72, 1987, 151-55. 
[15]. Sharma DC. Bhopal: 20 years on. Lancet, 365,2005,111-2.

[16]. Bhandari NR, Syal AK, Kambo I, Nair A, Beohar V, Sexena NC, et al. Pregnancy outcome in women exposed to toxic gas at Bhopal. Indian J Med Res,92, 1990,28-33.

[17]. Kamat SR, Patel MH, Kolhatkar VP, Dave AA, Mahashur AA. Sequential respiratory changes in those exposed to the gas leak at Bhopal. Indian J Med Res, 86, 1987, 20-38.

[18]. Indian Council of Medical Research. Annual Report, Bhopal Gas Disaster Research Centre. Bhopal: India; 1991.

[19]. Srinivasamurthy R, Isaac MK. Mental health needs of Bhopal disaster victims and training of medical officers in mental health aspects. Indian J Med Res , 86(Suppl), 1987, 51-58.

[20]. A report of WHO meeting on international collaborative research on craniofacial anomalies. Addressing the global challenges of craniofacial anomalies. Geneva 2004.

[21]. CSE Study: Contamination of soil and water inside and outside the Union Carbide India Limited, Bhopal.

[22]. Alaluusua, Satu; Lukinmaa, Pirjo-Liisa. Developmental dental toxicity of dioxin and related compounds: a review. International Dental Journal, 56 (6), 2006, 323-31.

[23]. Kakei M, Sakae T, Yoshikawa M. . Mechanism of cadmium induced crystal defects in developing rat tooth enamel. Proc Jpn Acad Ser B Phys Biol Sci, 85(10), 2009, 500-7. 